\title{
Analytic roughness prediction by deep rolling
}

\author{
B. Denkena ${ }^{1} \cdot$ A. Abrão ${ }^{2} \cdot$ A. Krödel ${ }^{1} \cdot K$. Meyer ${ }^{1}$
}

Received: 28 January 2020 / Accepted: 14 April 2020 / Published online: 30 April 2020

(c) The Author(s) 2020

\begin{abstract}
Deep rolling is a widely applied mechanical surface and subsurface treatment method. It is typically used after conventional machining to improve the roughness, increase the surface hardness and to induce compressive residual stresses. The main influence parameters on the surface topography are the applied deep rolling pressure, the ball diameter and the feed. In general, low feeds, larger ball diameters and higher pressures result in an even surface finish. However, an exact prediction of the roughness is not possible. Therefore, it is the aim of the presented research to find a generally applicable method for surface roughness prediction after deep rolling for a variety of steel and aluminum materials. It is shown that the surface topography can be predicted by an analytical model with high accuracy.
\end{abstract}

Keywords Deep rolling $\cdot$ Roughness $\cdot$ Surface topography $\cdot$ Roller burnishing

$\begin{array}{ll}\text { List of symbols } \\ d_{b} & \text { Ball diameter (mm) } \\ E & \text { Unified Young's modulus (GPa) } \\ f & \text { Feed (mm) } \\ F_{w} & \text { Deep rolling force }(\mathrm{N}) \\ h_{d} & \text { Peak distance }(\mathrm{mm}) \\ h_{r} & \text { Peak height }(\mathrm{mm}) \\ p_{m a x} & \text { Contact stress }(\mathrm{MPa}) \\ p_{w} & \text { Deep rolling pressure }(\mathrm{MPa}) \\ Q_{d e f} & \text { Stress ratio } p_{\text {max }} / R_{p 0.2}(-) \\ r & \text { Unified radius }(\mathrm{mm}) \\ r_{c} & \text { Contact radius }(\mathrm{mm}) \\ r_{\epsilon} & \text { Cutting edge radius }(\mathrm{mm}) \\ R_{p 0.2} & \text { Yield strength }(\mathrm{MPa}) \\ u & \text { Overlap factor }(-) \\ v_{r} & \text { Rolling speed }(\mathrm{m} / \mathrm{min})\end{array}$

K. Meyer

meyer_k@ifw.uni-hannover.de

B. Denkena

denkena@ifw.uni-hannover.de

A. Abrão

abrao@demec.ufmg.br

A. Krödel

kroedel@ifw.uni-hannover.de

1 Institute of Production Engineering and Machine Tools, Leibniz Universität Hannover, Hannover, Germany

2 Department of Mechanical Engineering, Federal University of Minas Gerais, Belo Horizonte, Brazil

\section{$\eta \quad$ Efficiency coefficient (-) \\ $\rho \quad$ Density $\left(\mathrm{g} / \mathrm{cm}^{3}\right)$}

\section{Introduction}

The surface topography plays a vital role for the functional behavior of metallic components. To guarantee the desired functionality of a component, it is often necessary to achieve a certain surface quality in form of a certain roughness. The manufacturing process deep rolling or roller burnishing, which is usually applied as a finishing process after cutting processes, offers the possibility for the surface quality improvement. A general observation is that deep rolling flattens the cutting-induced roughness peaks and that the roughness decreases using smaller feeds or higher ball diameters. One common method to describe the mechanical load applied by the deep rolling tool is the contact theory by Hertz [1]. Here, the contact stress during elastic deformation is considered. The following assumptions are common for the description of load stresses during deep rolling: Only elastic deformation, contact between two spherical objects [1]. The latter can be calculated for the more realistic contact case of a cylinder-sphere contact as performed by Maiß [2], but these adjustments results in minor and therefore negligible changes regarding the contact diameter. The calculation starts with an estimation of the deep rolling force $F_{w}$, which relates the deep rolling pressure $p_{w}$ to the contact area of half of the sphere: 
$F_{w}=p_{w} \cdot\left(\frac{d_{b}}{2}\right)^{2} \cdot \pi \cdot \eta$

$\eta$ is the efficiency coefficient, which can be assumed as $\eta=0.8$ as observed by Denkena et al. [3]. The contact radius $r_{c}$ is calculated by:

$r_{c}=\sqrt[3]{\frac{3 \cdot(1-v) \cdot r \cdot F_{w}}{2 \cdot E}}$

where $E$ is the unified Young's modulus and $R$ the unified radius:

$p_{\max }=\frac{1}{\pi} \cdot \sqrt[3]{\frac{1.5 \cdot F_{w}}{r_{c}^{2}} \cdot\left(\frac{E}{1-v^{2}}\right)^{2}}$

According to Klocke and Mader [4], the overlap factor $u$ has a high influence on different surface values. The overlap $u$ is a unitless factor, which relates the feed $f_{w}$ to the contact radius.

$u=1-\frac{f}{r_{c}}$

Klocke [5] reports a reduction of $30-50 \%$ on the peakto-valley height Rz machining quenched AISI52100 with a hardness of $62 \mathrm{HRC}$ using a deep rolling tool $d_{b}=6.35 \mathrm{~mm}$. Here, a flattening of peaks with no full surface deformation was observed. A similar result is achieved by Grzesik and Zak [6], who observed a roughness reduction after applying a deep rolling process to hard turned SAE5140, where remains of the turning induced profile are visible after the deep rolling process. Bouzid et al. [7] provide an analytic solution for the calculation of the resulting roughness after grinding and turning pre-treatments, which can play a role regarding the resulting surface after deep rolling. The initial topography is taken into account. Bouzid et al. [7] also observe no total deformation of the surface and roughness peaks of the pre-treatment are observable on the deep rolled surface. The results of Bouzid et al. and Grzesik contradict investigations on different materials as performed by $\mathrm{Li}$ et al. [8] for two different aluminum grades. According to $\mathrm{Li}$, depending on the feed and therefore the resulting overlap between each reversion, a total deformation induces the flattening of all initial roughness peaks. A possible reason for these different outcomes lies in differences in material and a load induced plastic deformations. Therefore, Li et al. consider the plastic deformation and achieve a higher agreement between predicted and machined roughness. All of the mentioned methods provide solutions for the used materials but lack a general explanation for different materials. It also remains unclear, if the prognosis of the surface topography can be performed with or without consideration of the initial workpiece topography. Therefore, this paper aims to find
Table 1 Material properties

\begin{tabular}{llll}
\hline Parameter & \multicolumn{2}{l}{ Material } & \\
\cline { 2 - 4 } & Al6082 & AISI1045 & AISI4140 \\
\hline Density $\rho$ & $2.83 \mathrm{~g} / \mathrm{cm}^{3}$ & $7.83 \mathrm{~g} / \mathrm{cm}^{3}$ & $7.72 \mathrm{~g} / \mathrm{cm}^{3}$ \\
Young's modulus E & $69 \mathrm{GPa}$ & $210 \mathrm{GPa}$ & $210 \mathrm{GPa}$ \\
Hardness & $158 \mathrm{HV} 1$ & $302 \mathrm{HV} 1$ & $515 \mathrm{HV} 1$ \\
Yield Strength $\mathrm{R}_{p 0.2}$ & $260 \mathrm{MPa}$ & $800 \mathrm{MPa}$ & $1,350 \mathrm{MPa}$ \\
\hline
\end{tabular}

Table 2 Parameters for the turning operations prior to the deep rolling process

\begin{tabular}{llll}
\hline Parameter & Material & & \\
\cline { 2 - 4 } & Al6082 & AISI1045 & AISI4140 \\
\hline Cutting depth $a_{p}$ & $0.4 \mathrm{~mm}$ & $0.3 \mathrm{~mm}$ & $0.65 \mathrm{~mm}$ \\
Feed $f$ & $0.1 \mathrm{~mm}$ & $0.1 \mathrm{~mm}$ & $0.1 \mathrm{~mm}$ \\
Cutting speed $v_{c}$ & $280 \mathrm{~m} / \mathrm{min}$ & $280 \mathrm{~m} / \mathrm{min}$ & $400 \mathrm{~m} / \mathrm{min}$ \\
\hline
\end{tabular}

a general analytical solution for the prediction of surface topographies after deep rolling. To create a solution, different materials are machined under variation of various process parameters. In comparison to the mentioned sources, the approach in this paper is to machine a variety of materials with different mechanical properties with a broad parameter variation.

\section{Experimental setup}

To investigate the influence of the deep rolling parameters on the surface topography, two sets of experiments were performed. While the first experimental stage aimed for a general analysis of the surface topography and the generation of a modelling method, the second stage aimed to evaluate the limitations of said method. To cover a wide range of materials, the experiments were performed using the steels AISI1045, AISI4140 and the aluminum alloy A16082 T5. The steels have been annealed to different hardness states. While the AISI4140 was quenched and tempered to 515 HV1, the AISI1045 was quenched to 302 HV1. The material properties are listed in Table 1. The yield strength was calculated according to Pavlina and van Tyne [9].

Prior to the deep rolling experiments, the samples were turned using Walter SNMA120408-RK5 cutting inserts. The parameters are listed in Table 2 . The experiments were conducted on a Gildemeister CTX 520 lathe using hydrostatic ECOROLL tools with HG3 (ball diameter $d_{b}=3.175$ $\mathrm{mm})$, HG6 $\left(d_{b}=6.35 \mathrm{~mm}\right)$ and $\operatorname{HG} 13\left(d_{b}=12.7 \mathrm{~mm}\right)$ tools with an adjustable compressor, which provides deep rolling pressures between $p_{w}=2-60 \mathrm{MPa}$. The forces 
were measured using a Kistler 9121 dynamometer. The surfaces were analyzed using a Mahr MarSurf LD 130 Perthometer.

In the first experimental stage, the workpieces were deep rolled using three different ball diameters $d_{b}$ and overlap factors $u$. To ensure a similar load and level of deformation, the maximum Hertzian pressure $p_{\max }$ was set in uniform relation to the yield strength $R_{p 0.2}$ Tंhis deformation ratio is defined as:

Table 3 Parameters used for the first set of experiments

\begin{tabular}{lllll}
\hline Parameter & Unit & \multicolumn{2}{l}{ Variation } & \\
\cline { 3 - 5 } & & - & 0 & + \\
\hline Ball diameter $d_{b}$ & $\mathrm{~mm}$ & 3.175 & 6.35 & 12.7 \\
Overlap factor $\mathrm{u}$ & $\%$ & -75 & 50 & 80 \\
Contact stress $p_{\max }$ & $\mathrm{MPa}$ & $7 \cdot R_{p 0.2}$ & & \\
Rolling speed $v_{r}$ & $\mathrm{~m} / \mathrm{min}$ & 100 & & \\
\hline
\end{tabular}

$Q_{d e f}=\frac{p_{\max }}{R_{p 0.2}}$

The calculation of the overlap factor $\mathrm{u}$ and $\mathrm{p}_{\max }$ was performed according to Eqs. 1 to 4 . The parameter variation is depicted in Table 3 . The resulting machining parameters for each experiment are depicted in Table 4.

The second set of experiments was performed afterwards to investigate limitations of the resulting analytical model. The ball diameter was set to a constant value of $d_{b}=6.35$ $\mathrm{mm}$ and the feed $f$ was varied between $f=0.05 \mathrm{~mm}$ and $f=0.8 \mathrm{~mm}$. The deep rolling pressure was varied in three stages for each material in order to induce different levels of deformation. The stress ratio $Q_{d e f}$ was taken to account in order to ensure a similar deformation on the different materials. Here, the limitations of the pump system regarding the deep rolling pressure $p_{w}$ range should be noted. The parameters for the second set of experiments are depicted in Table 5. As a result of said limitations, even lower $p_{w}$-values
Table 4 Parameters used for the first experimental stage

\begin{tabular}{|c|c|c|c|c|c|c|}
\hline & Rolling pressure & Feed & Ball diameter & Overlap factor & $\begin{array}{l}\text { Max. Hert- } \\
\text { zain stress }\end{array}$ & Stress ratio \\
\hline & $p_{w}$ & $\mathrm{f}$ & $d_{b}$ & $\mathrm{u}$ & $p_{\max }$ & $Q_{\text {def }}$ \\
\hline & $\mathrm{MPa}$ & $\mathrm{mm}$ & $\mathrm{mm}$ & - & $\mathrm{MPa}$ & - \\
\hline \multirow[t]{9}{*}{ AISI1045 } & 16 & 0.48 & 3.175 & -0.75 & 5890 & 7.36 \\
\hline & & 0.14 & & 0.5 & & \\
\hline & & 0.05 & & 0.8 & & \\
\hline & 14 & 0.91 & 6.35 & -0.75 & 5911 & 7.39 \\
\hline & & 0.26 & & 0.5 & & \\
\hline & & 0.1 & & 0.8 & & \\
\hline & 12 & 1.74 & 12.7 & -0.75 & 5908 & 7.39 \\
\hline & & 0.5 & & 0.5 & & \\
\hline & & 0.05 & & 0.8 & & \\
\hline \multirow[t]{9}{*}{ AISI4140 } & 56 & 0.32 & 3.175 & -0.75 & 8981 & 6.65 \\
\hline & & 0.09 & & 0.5 & & \\
\hline & & 0.04 & & 0.8 & & \\
\hline & 51 & 0.6 & 6.35 & -0.75 & 9013 & 6.68 \\
\hline & & 0.17 & & 0.5 & & \\
\hline & & 0.07 & & 0.8 & & \\
\hline & 41 & 1.14 & 12.7 & -0.75 & 9009 & 6.67 \\
\hline & & 0.33 & & 0.5 & & \\
\hline & & 0.2 & & 0.8 & & \\
\hline \multirow[t]{9}{*}{ Al6082 } & 3 & 0.25 & 3.175 & -0.75 & 1953 & 7.52 \\
\hline & & 0.07 & & 0.5 & & \\
\hline & & 0.03 & & 0.8 & & \\
\hline & 2.8 & 0.47 & 6.35 & -0.75 & 1959 & 7.53 \\
\hline & & 0.13 & & 0.5 & & \\
\hline & & 0.05 & & 0.8 & & \\
\hline & 2 & 0.87 & 12.7 & 0.75 & 1937 & 7.45 \\
\hline & & 0.25 & & 0.5 & & \\
\hline & & 0.05 & & 0.8 & & \\
\hline
\end{tabular}


Table 5 Parameters used for the second experimental stage

\begin{tabular}{|c|c|c|c|c|c|}
\hline & Rolling pressure & Feed & Ball diameter & $\begin{array}{l}\text { Max. Hertzain } \\
\text { stress }\end{array}$ & Stress ratio \\
\hline & $p_{w}$ & $\mathrm{f}$ & $d_{b}$ & $p_{\max }$ & $Q_{\text {def }}$ \\
\hline & $\mathrm{MPa}$ & $\mathrm{mm}$ & $\mathrm{mm}$ & MPa & - \\
\hline \multirow[t]{3}{*}{ AISI1045 } & 7 & $0.05-0.8$ & 6.35 & 4624 & 5.78 \\
\hline & 14 & & & 5824 & 7.28 \\
\hline & 40 & & & 8264 & 10.33 \\
\hline \multirow[t]{3}{*}{ AISI4140 } & 30 & $0.05-0.8$ & 6.35 & 7506 & 5.56 \\
\hline & 40 & & & 8264 & 6.12 \\
\hline & 50 & & & 8896 & 6.59 \\
\hline \multirow[t]{3}{*}{ Al6068 } & 2 & $0.05-0.8$ & 6.35 & 1731 & 6.66 \\
\hline & 5 & & & 2340 & 9 \\
\hline & 7.5 & & & 2678 & 10.3 \\
\hline
\end{tabular}

lead to a higher $Q_{d e f}$ for Al6082 than for AISI4140. Therefore, a lower deformation can be expected for the machined AISI4140.

\section{Results and discussion}

Figure 1 depicts the tactile measurement of deep rolled AISI1045 samples with the usage of three different overlap factors $(u=-75 \%, u=50 \%, u=80 \%)$. Also depicted is the turned surface to visualize the difference between the turned and the deep rolled surface. The tool diameter was $d_{b}=3.175 \mathrm{~mm}$. On the left hand side, the turned surface is indicated by the typical periodic cutting profile. In the center, the first contact position between deep rolling ball and workpiece is visible. Because of the toolpath, which provides a linear feed into the contact position with the hydrostatic pressure already attached, there is a deeper groove compared to the following position. The upper graph shows the negative overlap of $u=-75 \%$. This means that no section of material comes into double contact with the workpiece. The underlying principle of volume constancy in forming processes results in a high penetration depth and width. Also visible are the peaks induced by the previous turning operation. This part of the material is not deformed and the roughness peaks are not flattened.

Figure 2 shows the deep rolled part of the AISI1045 samples. Here, the full variation of ball diameters using the different overlap factors is shown. For each ball diameter, using the overlap factor of $u=-75 \%$, roughness peaks from the previous turning operation are visible. With increasing ball diameter and consistent pressure, a higher penetration depth and width is visible because of the higher process forces. This this results in a higher necessary feed $f$ to achieve the overlap factors. Using the overlap factor of $u=50 \%$, the profile is periodic with each ball diameter. Because of the larger ball diameter $d_{b}$ and
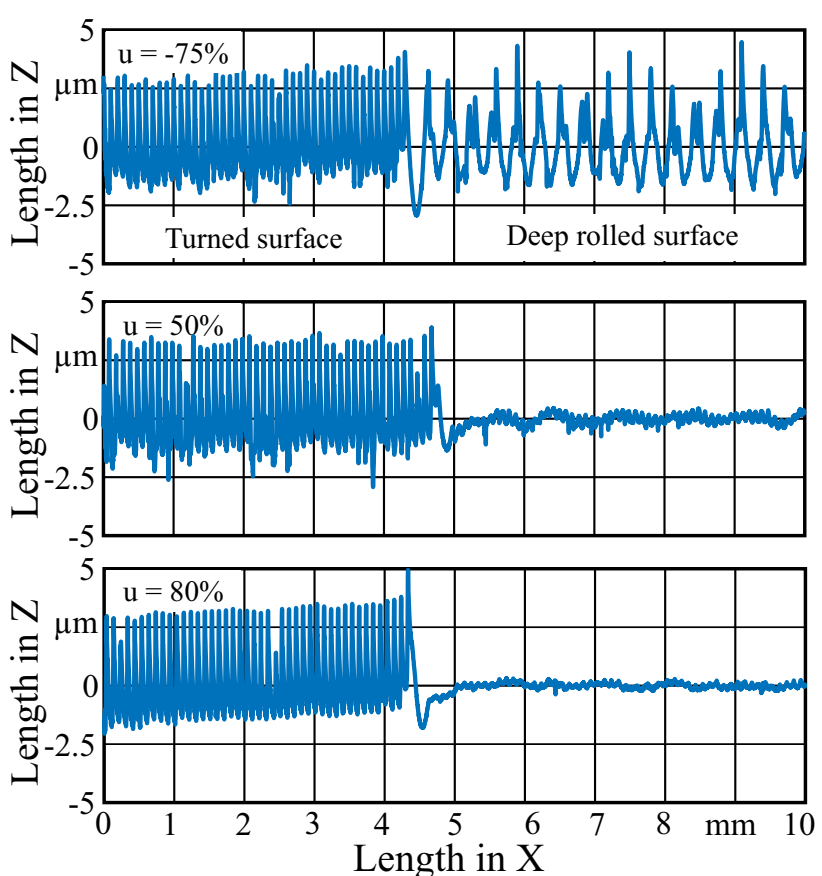

\begin{tabular}{lll}
\hline Deep rolling & Tool: & ECOROLL HG3 \\
Pressure: $\mathrm{p}_{\mathrm{W}}=16 \mathrm{MPa}$ & Ball diameter: & $\begin{array}{l}\mathrm{d} \mathrm{b}=3.175 \mathrm{~mm} \\
\text { Feed: } \mathrm{f}=0.32|0.09| 0.04 \mathrm{~mm} \\
\text { Material: }\end{array}$ ceramic \\
Overlap: $\mathrm{u}=-75|50| 80 \%$ & Workpiece: & AISI1045 \\
& Hardness: & $302 \mathrm{HV} 1$ \\
& & My/93259@ IFW
\end{tabular}

Fig. 1 Surface topography after turning and subsequent deep rolling of AISI1045

the increasing feed $f$ to achieve the same overlap factor, the distance between the peaks increases. The surface after a deep rolling procedure under the usage of an overlap factor of $u=80 \%$ does not show periodicity. The visual representation does not allow a statement about peak height or distance distribution. It is also visible, that a similar roughness $R z$ occurs regardless of the ball diameter (Fig. 3). The resulting profiles from the deep rolling of 

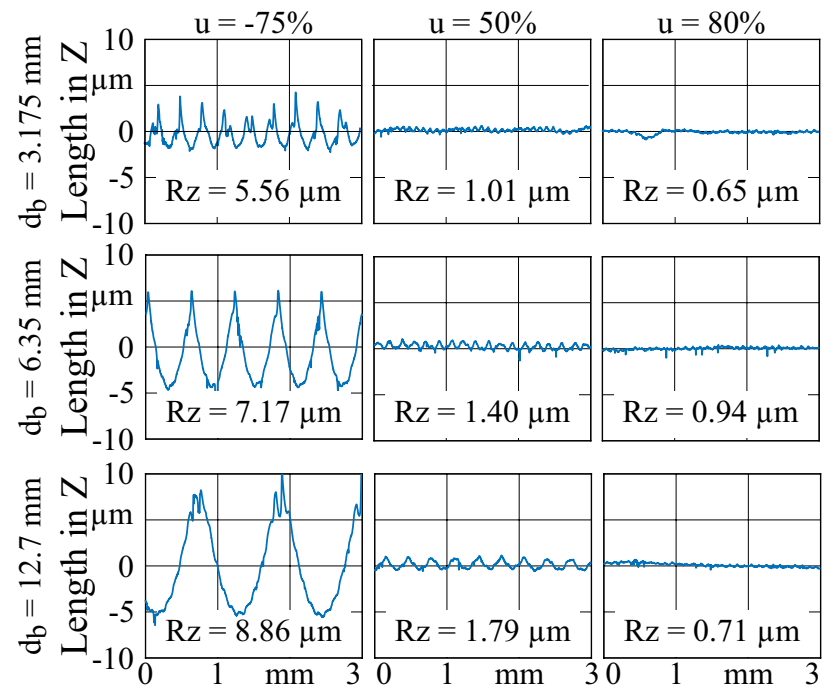

Length in $\mathrm{X}$ Length in $\mathrm{X}$ Length in $\mathrm{X}$

\begin{tabular}{|c|c|c|}
\hline Deep rolling & Tool: & ECOROLLHGX \\
\hline Pressure: $\mathrm{p}_{\mathrm{W}}=$ var. & Ball diameter: & $\mathrm{d}_{\mathrm{b}}=$ var. \\
\hline Feed: $\quad \mathrm{f}=$ var. & Material: & ceramic \\
\hline Overlap: & 50|80\% Workpiece: & AISI1045 \\
\hline
\end{tabular}

My/93274@IFW

Fig. 2 Development of the surface topography on AISI1045 with alternating overlaps and ball diameters
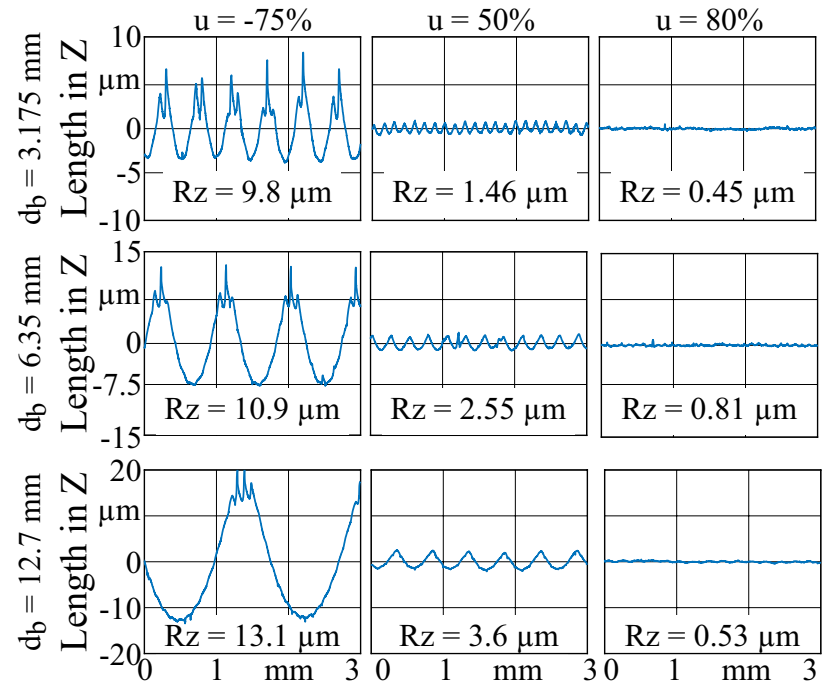

Length in $X$ Length in $X$ Length in $X$

\begin{tabular}{|c|c|c|}
\hline Deep rolling & Tool: & ECOROLLHGX \\
\hline Pressure: $\mathrm{p}_{\mathrm{W}}=$ var. & Ball diameter: & $\mathrm{d}_{\mathrm{b}}=$ var. \\
\hline Feed: $\quad \mathrm{f}=$ var. & Material: & ceramic \\
\hline $\mathrm{u}=-75|50| 80 \%$ & $\begin{array}{l}\text { Workpiece: } \\
\text { Hardness: }\end{array}$ & $\begin{array}{l}\text { AISI4140 } \\
515 \text { HV1 } \\
\text { My/93275 @ IFW }\end{array}$ \\
\hline
\end{tabular}

Fig. 3 Development of the surface topography on AISI4140 with alternating overlaps and ball diameters the Al6082 samples look slightly different, as displayed in Fig. 4. While the resulting surface using an overlap factor of $u=-75 \%$ for the ball diameters $d_{b}=6.35 \mathrm{~mm}$ and $d_{b}=12.7 \mathrm{~mm}$ looks similar to those on the AISI1045 and AISI4140 samples, $d_{b}=3.175 \mathrm{~mm}$ does not create such a clear periodic profile with visible turning peaks. This behavior can be explained by the comparably small feed $\mathrm{f}$ which is necessary to achieve an overlap of $u=-75 \%$. The surface profiles for $u=50 \%$ are also periodically distributed and show a line of round indentations, while $u=80 \%$ creates a smooth surface with no obvious periodic characteristic. These results indicate that independent of the plastic material behavior, a higher overlap factor and a larger ball diameter $d_{b}$ leads to a smoother surface, which is also a general conclusion of the state of the art. It can also be seen, that both, deep rolled and turned surfaces have seemingly periodically distributed peaks. In the case of a negative overlap factor $u$, the remaining peaks from turning process are between the grooves from deep rolling.

A similar behavior can be seen for the same treatment applied to the AISI4140. Using the negative overlap factor $u=-75 \%$, the round indentations are intermitted by the peaks created by the turning process. The profile created using overlap of $u=50 \%$ is also periodic. The profile created using $u=80 \%$ does not display an obviously periodic profile and similar roughness values $R z$.
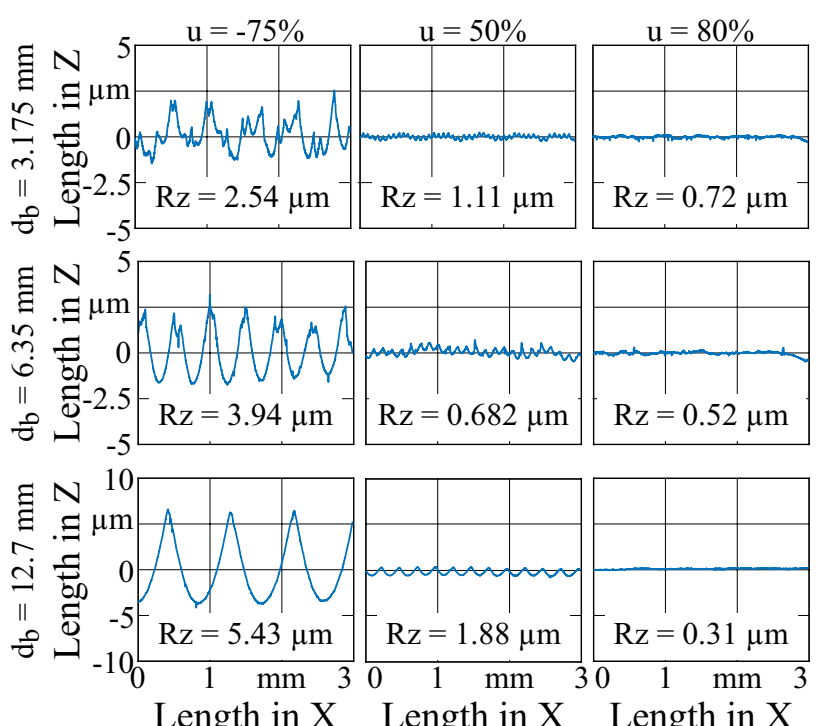

\begin{tabular}{|c|c|c|}
\hline $\begin{array}{l}\text { Deep rolling } \\
\text { Pressure: } p_{\mathrm{W}}=\text { var. } \\
\text { Feed: } \quad \mathrm{f}=\text { var. } \\
\text { Overlap: } \quad \mathrm{u}=-75|50| 80 \%\end{array}$ & $\begin{array}{l}\text { Tool: } \\
\text { Ball diameter: } \\
\text { Material: }\end{array}$ & $\begin{array}{l}\text { ECOROLL HGX } \\
d_{b}=\text { var. } \\
\text { ceramic }\end{array}$ \\
\hline
\end{tabular}

Fig. 4 Development of the surface topography on A16082 with alternating overlaps and ball diameters 


\section{Analytic model}

Because some of the surfaces generated by deep rolling showed a periodic profile with round indentations, the measurements were analyzed using a Fast Fourier Transformation (FFT) algorithm to find links between the manufacturing process and the resulting surface. Figure 5 shows the resulting surface topographies and the Fourier transformations for Al6082 with an ECOROLL HG13 deep rolling tool. For the overlap factors $u=-75 \%$ and $u=50 \%$, the reciprocal of the dominant wavelength $x_{\max }$ is equal to the feed $f$ set during the deep rolling process. This correlation is not discernible with an overlap factor of $u=80 \%$. A possible explanation may be a material pile up which results from plastic deformation in combination with the close iterations resulting from the feed $f$. The congruence between a ball geometry and the surface is also shown.

Here, the spherical contour is elliptically represented by the length distortion between the axes. The good optical fit for the overlap factors $u=-75 \%$ and $u=50 \%$ shows that the generated surface is a repeated pattern of nearly spherical indentation. The deviation between ball contour and the indentation may result from elastic springback, and the remaining surface is plastically deformed. With regard to those results, the resulting surface for the overlap of $u=50 \%$ can be described by the indentation geometry of the tool. The Fourier analysis showed that the impressions are formed at regular intervals corresponding to the feed rate for $u=-75 \%$ and $u=50 \%$. A reproduction of the surface using ball diameter $d_{b}$ and feed $f$ is however only possible for $u=50 \%$, because a negative overlap leads to undeformed peaks in between the spherical profiles. Regardless of material or $d_{b}$, the surface for $u=50 \%$ can be simulated using an intersection of spheres which are aligned in the distance of the feed $f$. As an example, and proof of concept, Fig. 6 shows a comparison between the deep rolled surface and a surface generated by the above mentioned method implemented in a Matlab model. To describe the height of the peaks for applicable process parameters, a simple geometrical model, comparable to the calculation of the theoretical roughness during turning can be used. This procedure is described in Eqs. 6 and 7. To calculate the peak height $h_{r}$, the first step is to calculate the difference $h_{d}$ between the ball radius $d_{b} / 2$ and $h_{r}$. This is performed using the Pythagorean theorem
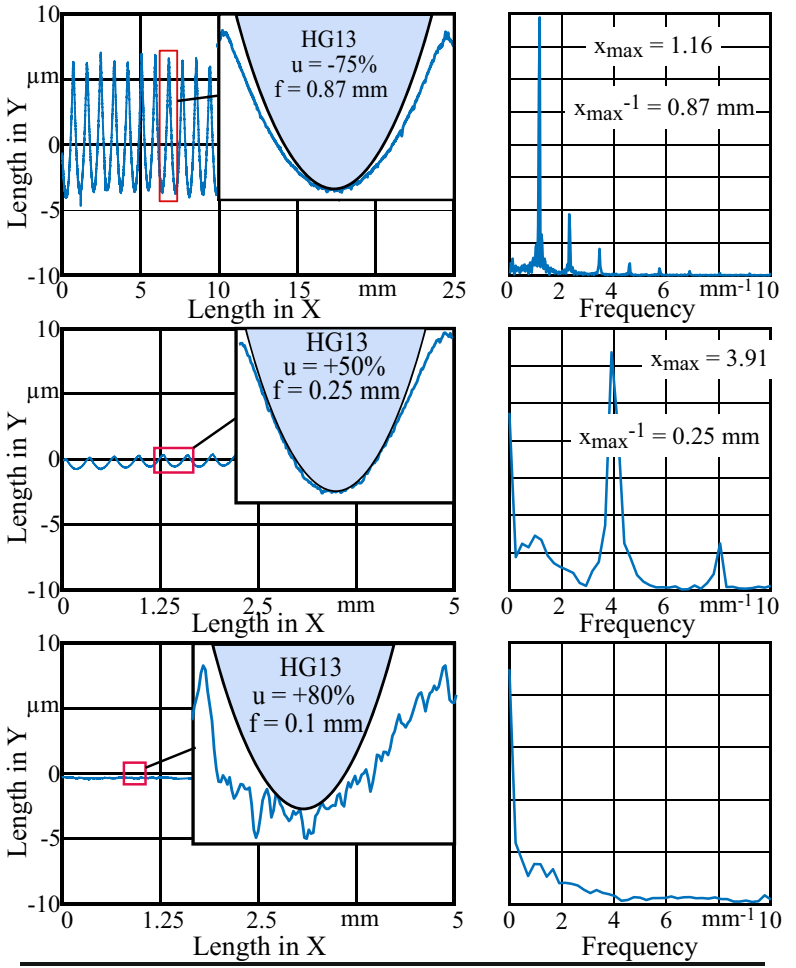

\begin{tabular}{lll}
\hline Deep rolling & Tool: & ECOROLLHG13 \\
Pressure: $\mathrm{p}_{\mathrm{w}}=2.2 \mathrm{MPa}$ & Ball diameter: & $\mathrm{d}_{\mathrm{b}}=12.7 \mathrm{~mm}$ \\
Feed: $\mathrm{f}=0.87|0.25| 0.1 \mathrm{~mm}$ Material: & ceramic \\
Overlap: $\mathrm{u}=-75|50| 80 \%$ & Workpiece: & Al6082 \\
& & My/93260 @ IFW
\end{tabular}

Fig. 5 Periodic representation of the feed in deep rolled surfaces

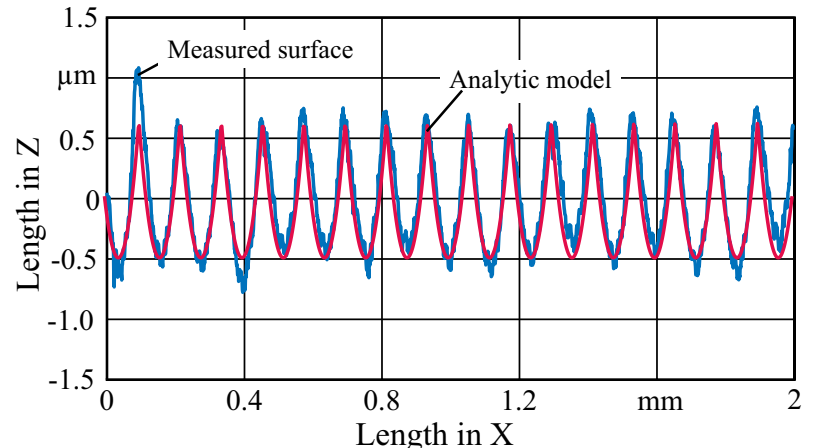

\begin{tabular}{llll}
\hline Deep rolling & Tool: & ECOROLL HG3 \\
Pressure: & $\mathrm{p}_{\mathrm{w}}=5.6 \mathrm{MPa}$ & Ball diameter: & $\mathrm{d} \mathrm{b}=3.175 \mathrm{~mm}$ \\
Feed: & $\mathrm{f}_{\mathrm{w}}=0.14 \mathrm{~mm}$ & Material: & ceramic \\
Overlap: $\quad \mathrm{u}=50 \%$ & Workpiece: & AISI4140 \\
& & Hardness: & $515 \mathrm{HV} 1$ \\
& & & My/93261 @ IFW
\end{tabular}

Fig. 6 Analytic model for the deep rolling of quenched AISI4140

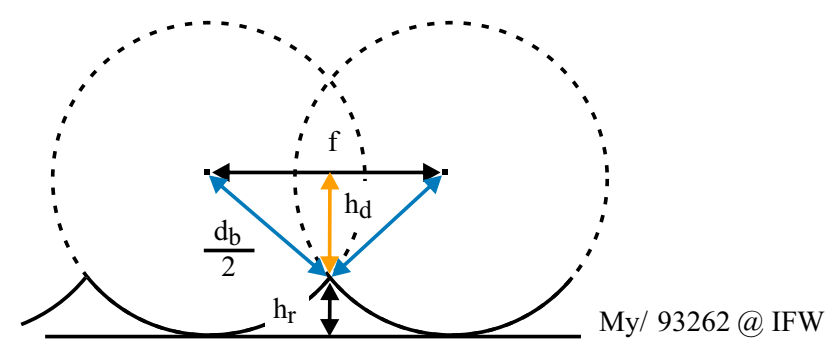

Fig. 7 Calculation of the peak height 
for the two same-sized right-angled triangles between both center points and the intersection of both spheres (Fig. 7).

$$
\begin{aligned}
& h_{d}=\sqrt{\left(\frac{d_{b}}{2}\right)^{2}-\left(\frac{f}{2}\right)^{2}} \\
& h_{r}=\frac{d_{b}}{2}-h_{d}=\frac{d_{b}}{2}-\sqrt{\left(\frac{d_{b}}{2}\right)^{2}-\left(\frac{f}{2}\right)^{2}}
\end{aligned}
$$

The first set of experiments showed a possibility to determine the resulting surface after a deep rolling process. The experiments showed that the surfaces with an overlap factor of $u=50 \%$ are well predictable using this simple geometric relationship. The description of a negative overlap is not possible because some parts of the surface are not in contact with the tool and therefore not plastically deformed. This results in a helical groove track around the workpiece. A possible limit could lie in the pressure and therefore the resulting ratio $Q_{d e f}$. On the observed workpieces, the applied pressure $p_{w}$ provides sufficient deformation in a nearly spherical area, which is greater in comparison to the feed. In order to investigate the influence of the pressure $p_{w}$ and to investigate a suitable feed range, the next chapter focusses on a broader parameter variation in order to verify this model.

\section{Experimental verification of the model}

The first chapters demonstrate promising results regarding the description of the surface topography after deep rolling with overlap factors, calculated following the Hertzian contact theory of $u=50 \%$. To find the limitations of the mentioned approach, all three materials were again turned and deep rolled using the parameters described in Table 5. In order to provoke different levels of plastic deformation, the deep rolling pressure $p_{w}$ was varied in three stages with alternating feeds.

The resulting surfaces were analyzed regarding the Roughness $R z$ and compared with the analytically calculated surfaces. Figure 8 shows the comparison for AISI1045. The $\mathrm{x}$-axis represents the feed and the $\mathrm{y}$-axis the Roughness $R z$. $R z$ was determined by an analysis of an analytically calculated surface created with the above mentioned method. For the machining of AISI1045, pressures of $p_{w}=7 \mathrm{MPa}, 14 \mathrm{MPa}$ and $40 \mathrm{MPa}$ were used. An accordance of $76 \%$ between the geometric model and the measured roughness is calculated for feed rates between $f=0.05-0.3 \mathrm{~mm}$. By using a higher feed, the difference between the analytical roughness and the experimentally obtained profile increases with lower pressures. This behavior is illustrated in Fig. 9 for a feed of $f=0.2 \mathrm{~mm}$.

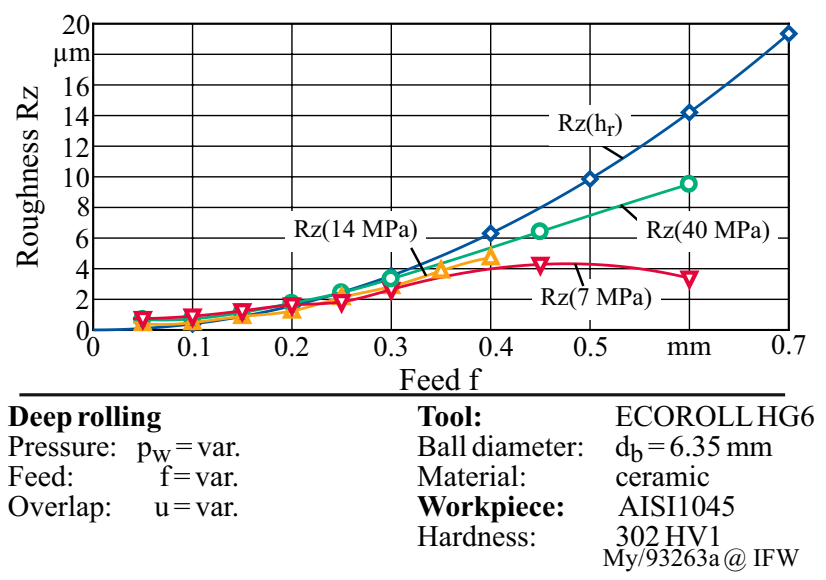

Fig. 8 Theoretical vs. experimental roughness for AISI1045

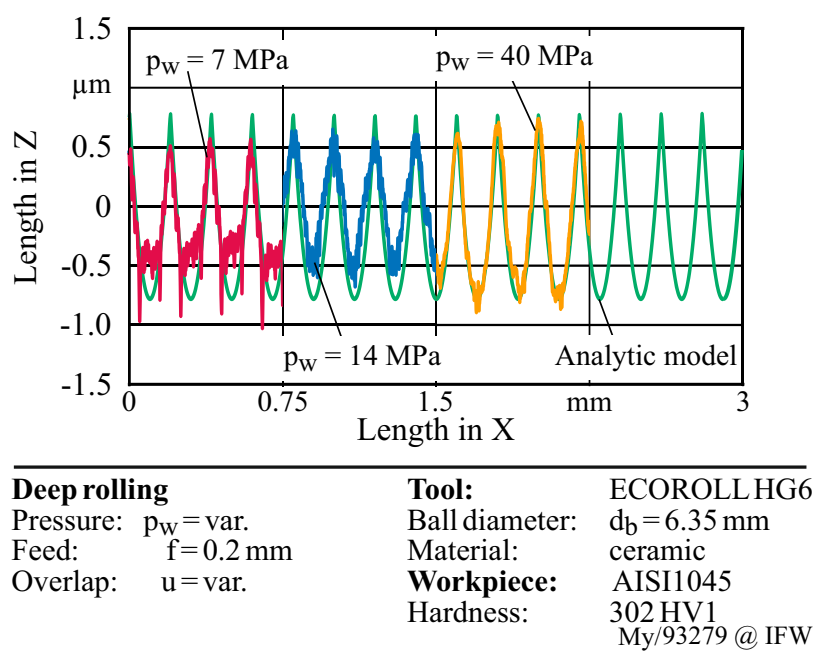

Fig. 9 Surfaces after deep rolling with alternating pressures $\mathrm{p}_{w}$

The first segment focusses on the surface generated by the rolling pressure $p_{w}=7 \mathrm{MPa}$ and $Q_{\text {def }}=5.78$. Here, a distortion is visible on the bottom position of the groove. This distortion is caused by the relatively low pressure which induces a comparably low level of deformation. Therefore, the indentation depth does not reach the calculated depth. This results in minor deviation to the calculated roughness $R z$ but should be taken into account. A similar behavior is visible for $p_{w}=14 \mathrm{MPa}$. Here, the groove is also distorted. The peak height is a little higher in comparison to $p_{w}=7 \mathrm{MPa}$. Using the higher pressure of $p_{w}=40 \mathrm{MPa}$, the indentation depth as well as the peak height matches the analytically calculated surface in a high degree. This leads to the conclusion, that $Q_{\text {def }}>7.28$ is necessary for the application of the analytical model to AISI1045 with 30 HRC. An exact value has to be determined experimentally. 
Using a feed over $f=0.3 \mathrm{~mm}$, the theoretical roughness increases in comparison to the experimentally generated roughness. The difference is higher when using lower pressures. Figure 10 depicts the surfaces after deep rolling using $f=0.45 \mathrm{~mm}$ to illustrate the differences of the surface topography using $p_{w}=7 \mathrm{MPa}$ and $40 \mathrm{MPa}$. The surface generated by $p_{w}=7 \mathrm{MPa}$ is comparable with the negative overlap described in the previous chapters: The initial turning induced peaks are not fully deformed. Resulting from the low degree of deformation, the grooves are not deep enough to reach the level of the analytically calculated surface. This combination results in a helical projection of the sphere's geometry on the workpiece surface. Using $p_{w}=40 \mathrm{MPa}$, the surface is still fully deformed. The material is built up to a higher peak height. This results in a higher roughness and therefore a closer similarity to the analytic model.

It should however be noted that a deep rolling process with the goal of surface improvement is not a matter of interest for roughness values over $R z=4 \mu \mathrm{m}$. Therefore, the region of interest can be changed to feed values under $f=0.3 \mathrm{~mm}$ in order to improve the visibility of the illustration.

With this change of focus on lower feeds $f$ and resulting roughness values $\mathrm{Rz}$, the above described behavior can be confirmed, as visualized in Fig. 11. It should however be noted, that below $f=0.1 \mathrm{~mm}$, the simple geometric model underestimates the roughness for $p_{w}=7 \mathrm{MPa}$ and $p_{w}=40$ $\mathrm{MPa}$. The difference is lower for $p_{w}=14 \mathrm{MPa}$. Concerning these results, no clear influence of the deep rolling pressure $p_{w}$ can be detected. Further investigations have to be performed in order to explain this behavior.

The application of the parameter variation leads to a similar surface progression on the other investigated materials. Machining the harder and therefore less plastic AISI4140 achieves a similar result, as indicated in Fig. 12. Here, the

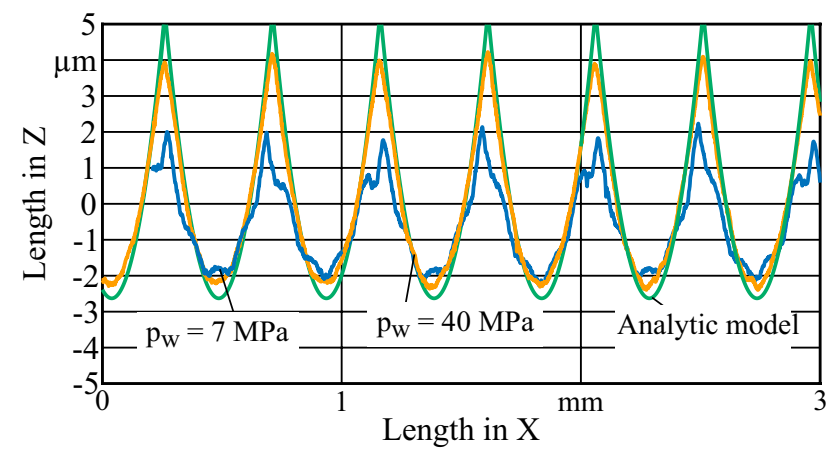

\begin{tabular}{|c|c|c|}
\hline Deep rolling & Tool: & ECOROLLHG6 \\
\hline Pressure: $p_{\mathrm{W}}=$ var. & Ball diameter: & $\mathrm{d}_{\mathrm{b}}=6.35 \mathrm{~mm}$ \\
\hline Feed: $\quad \mathrm{f}=0.45 \mathrm{~mm}$ & Material: & ceramic \\
\hline Overlap: $\quad \mathrm{u}=$ var. & Workpiece: & $\begin{array}{l}\text { AISI1045 } \\
\text { My/93280@IFW }\end{array}$ \\
\hline
\end{tabular}

Fig. 10 Surfaces after deep rolling with alternating pressures $p_{w}$

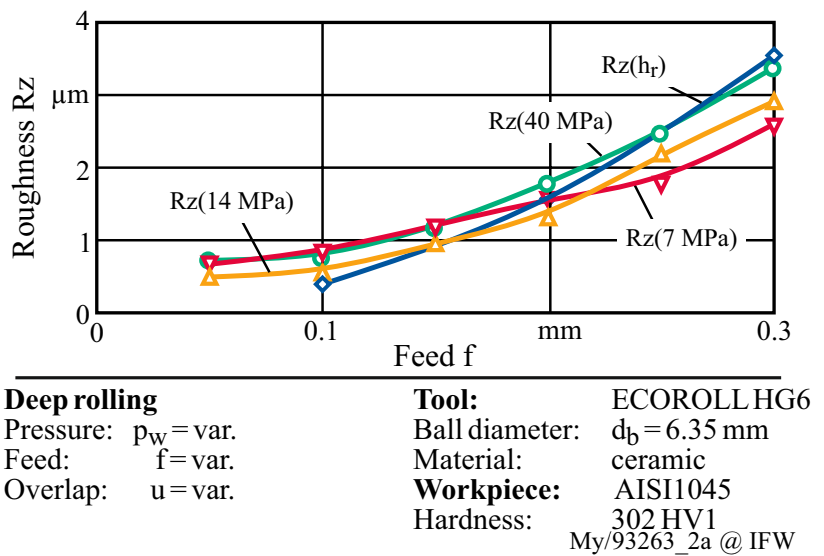

Fig. 11 Theoretical vs. experimental roughness for AISI1045 with focussed ROI

point of a differentiation between model and experimental surface is at $f=0.2 \mathrm{~mm}$ and therefore lower than for AISI1045. This result can be explained by the different plastic behavior of this harder material. Also visible is a higher accordance between model and experiment for $f>0.1 \mathrm{~mm}$. In this range, the estimated roughness is higher for the lower deep rolling pressure of $p_{w}=30 \mathrm{MPa}$. This can be explained by the lower induced plastic deformation. It should also be mentioned that due to the above mentioned limitations of the compressor, the highest achieved ratio $\mathrm{Q}_{\text {def }}=6.59$ is lower than the lowest possible ratio for $\operatorname{Al} 6082\left(Q_{\text {def }}=6.66\right)$. It can be concluded, that the model requires further adaptation for materials with high mechanical strength. Here, the approach of Bouzid et al. [7], where the plastic deformation is more carefully taken into account, could be applied. Another Option would be to increase the deep rolling pressure $p_{w}$ to generate a higher $Q_{\text {def }}$. This approach is limited by the available compressor system.

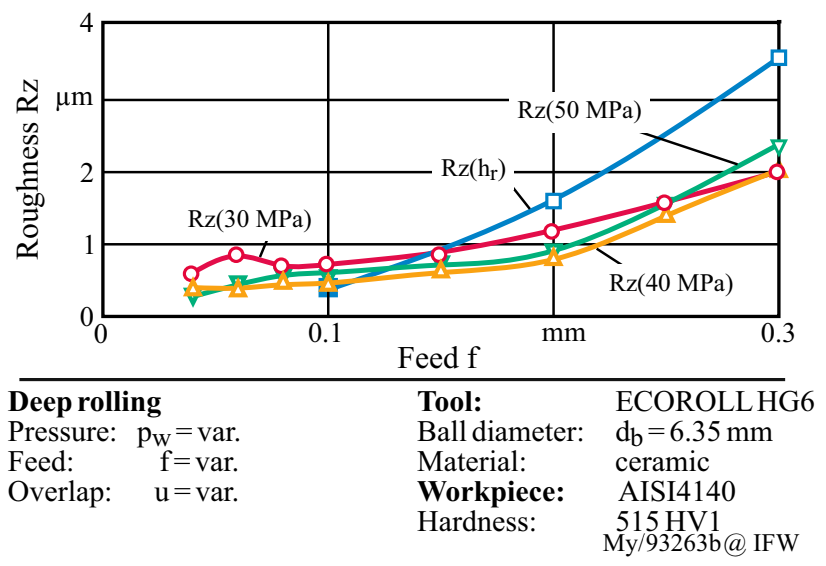

Fig. 12 Theoretical vs. experimental roughness for AISI4140 


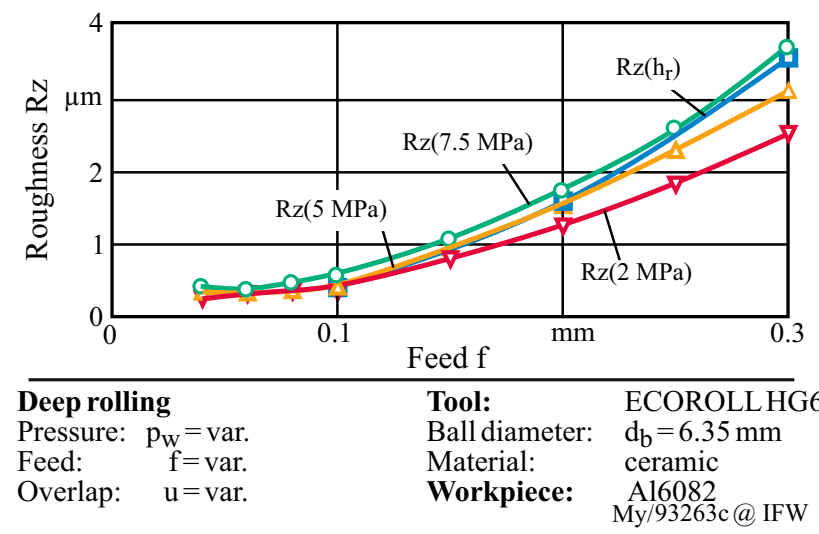

Fig. 13 Theoretical vs. experimental roughness for A16082

To study the behavior of softer materials and compare the model for the Al6082, a repetition of the experiment was performed using pressures of $p_{w}=2,5$ and 7.5 MPa. As depicted in Fig. 13, the resulting surface topography is represented up to a feed of $f=0.3 \mathrm{~mm}$. The highest accordance of $93 \%$ is achieved using $p_{w}=7.5 \mathrm{MPa}$ which results in $Q_{\text {def }}=10.3$. With lower $Q_{d e f}$, the difference increases. Only small improvements of the resulting roughness are observed for every material below $f=0.1 \mathrm{~mm}$. Under the single-handed consideration of the roughness, smaller feeds are not recommended because they would increase process times in an industrial machining scenario. However, by reducing the feed, it is possible to further improve the residual stress state, especially regarding the residual stress-depth distribution as observed by Kämmler et al. [10]. A combined model for residual stresses and roughness could be used in industrial applications to optimize the relation between machining time and obtained result.

\section{Conclusion and outlook}

To predict the roughness of deep rolled surfaces for different materials, a geometry and deformation based model was designed following indications of the possibility to describe a two-dimensional tactile measurement by the intersection of spheres. This model was tested for a wide range of possible machining parameters and for three different materials. To describe the groove created by the deep rolling process according to this theory, a full deformation is necessary. The tendency for deformation can be described by $Q_{d e f}$, the quotient of the maximum Hertzian pressure $p_{\max }$ and the yield strength $R_{p 0.2}$. Concluding from the experiments, $Q_{\text {def }}>7$ was necessary. For the used setup, it was therefore possible to describe the surface for the softer materials Al6082 and AISI1045. The used compressor did not provide sufficient pressure $p_{w}$ to achieve this criterion for quenched and tempered AISI4140. Another limit lies in the feed. The model worked below feeds of $f<0.3 \mathrm{~mm}$. A further increase in feed rate would cause the maximum indentation width to be exceeded and complete deformation would not occur. Another point of focus should be the initial roughness state. In this paper, turning was used before the deep rolling process. These can also be influenced systematically by a variation of the feed $f$ or the edge radius $r_{\epsilon}$. Further research could also apply this method to ground workpieces.

Acknowledgements Open Access funding provided by Projekt DEAL. The authors would like to thank the German (DFG) and the Brazilian Research Foundation (CAPES) for the funding of the common BRAGECRIM-project "Influence of the manufacturing process on the subsequent residual stress relaxation in AISI4140 steel", which was funded under the Grant number DE447/128-2.

\section{Compliance with ethical standards}

Conflict of interest The authors declare that they have no conflict of interest.

Open Access This article is licensed under a Creative Commons Attribution 4.0 International License, which permits use, sharing, adaptation, distribution and reproduction in any medium or format, as long as you give appropriate credit to the original author(s) and the source, provide a link to the Creative Commons licence, and indicate if changes were made. The images or other third party material in this article are included in the article's Creative Commons licence, unless indicated otherwise in a credit line to the material. If material is not included in the article's Creative Commons licence and your intended use is not permitted by statutory regulation or exceeds the permitted use, you will need to obtain permission directly from the copyright holder. To view a copy of this licence, visit http://creativecommons.org/licenses/by/4.0/.

\section{References}

1. Meyer D, Kämmler J (2016) Surface integrity of aisi 4140 after deep rolling with varied external and internal loads. Proc CIRP 45:363-366

2. Maiß O (2019) Lebensdauererhöhung bei Wälzlagern durch mechanische Bearbeitung: Dr.-Ing. Dissertation, Leibniz Universität Hannover

3. Denkena B, Grove T, Breidenstein B, Abrão A, Meyer K (2018) Correlation between process load and deep rolling induced residual stress profiles. Proc CIRP 78:161-165. https://doi. org/10.1016/j.procir.2018.09.063 ISSN 22128271

4. Klocke F, Mader S (2005) Fundamentals of the deep rolling of compressor blades for turbo aircraft engines. Steel Res Int 76(2-3):229-235

5. Klocke F, Liermann J (1998) Roller burnishing of hard turned surfaces. Int J Mach Tools Manuf 38(5-6):419-423

6. Grzesik W, Żak K (2012) Modification of surface finish produced by hard turning using superfinishing and burnishing operations. J Mater Process Technol 212(1):315-322. https://doi.org/10.1016/j. jmatprotec.2011.09.017 ISSN 0924-0136

7. Bouzid W, Tsoumarev O, Sai K (2004) An investigation of surface roughness of burnished aisi1042 steel. Int J Adv Manuf Technol 24(1-2):120-125. https://doi.org/10.1007/s00170-003-1761-4 ISSN 0268-3768

8. Li FL, Xia W, Zhou ZY, Zhao J, Tang ZQ (2012) Analytical prediction and experimental verification of surface roughness during 
the burnishing process. Int J MachTools Manuf 62:67-75. https:// doi.org/10.1016/j.ijmachtools.2012.06.001 ISSN 08906955

9. Pavlina EJ, van Tyne CJ (2008) Correlation of yield strength and tensile strength with hardness for steels. J Mater Eng Perform 17(6):888-893. https://doi.org/10.1007/s11665-008-9225-5 ISSN 1059-9495

10. Kämmler J, Wielki N, Meyer D (2018) Surface integrity after internal load oriented multistage contact deep rolling. Proc CIRP
71:490-495. https://doi.org/10.1016/j.procir.2018.05.026 ISSN 22128271

Publisher's Note Springer Nature remains neutral with regard tojurisdictional claims in published maps and institutional affiliations. 